\title{
Equipos de protección personal y métodos de capacitación con menor riesgo de autocontaminación o infección en el personal sanitario
}

Personal protection equipment and training methods with the lowest risk of self-contamination or infection in healthcare personnel

\section{Comentado de:}

Verbeek JH et al. Cochrane Database of Systematic Reviews 2020, Issue 4. Art. No.: CD011621. PMID: $32293717^{1}$

\section{Introducción}

En epidemias de enfermedades altamente infecciosas, como la enfermedad por el virus del Ébola (EVD), el síndrome respiratorio agudo severo (SARS), o la enfermedad por coronavirus SARSCoV-2 (COVID-19), el personal de la salud (PS) tiene un riesgo mayor de infección que la población en general, debido a su contacto con los fluidos corporales contaminados de los pacientes. Las precauciones de contacto mediante equipos de protección personal (EPP) pueden reducir ese riesgo. No está claro qué tipo de EPP protege mejor, cuál es la mejor forma de quitarlo y cómo capacitar al PS para usar el EPP según las instrucciones.

\section{Objetivos}

Evaluar qué tipo de EPP de cuerpo completo y qué método de ponerse o quitarse el EPP tienen menor riesgo de autocontaminación o infección para el PS, y qué métodos de capacitación aumentan el cumplimiento de los protocolos de EPP.

\section{Métodos de búsqueda}

Se realizaron búsquedas en CENTRAL, MEDLINE, Embase y CINAHL hasta el 20 de marzo de 2020.

\section{Criterios de selección y análisis de datos}

Se incluyeron todos los ensayos controlados que evaluaron el efecto del EPP de cuerpo completo utilizado por el PS expuesto a enfermedades altamente infecciosas, en el riesgo de infección, contaminación o incumplimiento de los protocolos. También se incluyeron los estudios que compararon el efecto de varias formas de ponerse o hacer EPP, y los efectos de la capacitación sobre los mismos resultados.

Dos revisores seleccionaron de forma independiente los estudios, extrajeron los datos y evaluaron el riesgo de sesgo en los ensayos incluidos. Se realizo metanálisis de randome.ects cuando fue apropiado.

\section{Resultados}

Esta es una actualización de una revisión Cochrane publicada en 2016 y actualizada previamente en 2019. Incluyó 24 estudios con 2.278 participantes, de los cuales 14 fueron ensayos controlados aleatorizados (ECA), uno fue un ECA cuasi-aleatorizado y nueve tuvieron un diseño no aleatorizado.

La evidencia de todos los resultados es de muy baja certeza, basados en uno o dos estudios, con evidencia indirecta proveniente de estudios de simulación y con elevado riesgo de sesgo.

\section{Tipos de equipo de protección personal}

El uso de un respirador eléctrico purificador de aire con overol puede proteger mejor contra el riesgo de contaminación que una máscara N95 y una bata (Riesgo Relativo [RR] 0,27; intervalo de confianza [IC] del 95\%: 0,17 a 0,43) pero fue más difícil de cumplir (incumplimiento: RR 7,5; IC 95\% 1,81 a 31,1). En un ECA (59 participantes), las personas con una bata larga tenían menos contaminación que aquellas con un overol, y los overoles eran más difíciles de quitar (evidencia de baja certeza).

Las batas podrían proteger mejor contra la contaminación que los delantales (diferencia media [DM] -10,28; IC 95\%: -14,77 a $-5,79$ ). El EPP hecho de material más transpirable puede dar lugar a un número similar de manchas en el tronco (DM 1,60; IC $95 \%-0,15$ a 3,35 ) en comparación con material más repelente al agua, pero puede tener una mayor satisfacción del usuario (DM $-0,46$; IC $95 \%$ : $-0,84$ a $-0,08$, en una escala de 1 a 5).

El uso de un respirador purificador de aire motorizado podría proteger mejor que un conjunto simple de EPP sin este tipo de respirador (RR 0,27; IC $95 \%$ : 0,17 a 0,43).

Las siguientes modificaciones en el diseño del EPP podrían conducir a una menor contaminación en comparación con el EPP estándar: pestañas adicionales para agarrar máscaras (RR 0,33 ; IC $95 \%$ : 0,14 a 0,80) o guantes (RR 0,22; IC $95 \%$ : 0,15 a 0,31), una combinación sellada de bata y guante (RR 0,27; IC $95 \%$ : $0,09$ a 0,78$)$, o una bata más ajustada alrededor del cuello, las muñecas y las manos (RR 0,08; IC 95\%: 0,01 a 0,55).

\section{Cuidados al retirar el equipo de protección}

Seguir las recomendaciones del Centro para el Control de Enfermedades de los EE.UU. (CDC) para la retirada puede conducir a una menor contaminación en comparación con ninguna guía (DM 5,44; IC 95\% -7,43 a -3,45).

La eliminación de guantes y batas en un solo paso podría dar lugar a una menor contaminación bacteriana (RR 0,20; IC 95\%: $0,05$ a 0,77$)$ pero no a menor contaminación fluorescente (RR 0,98; IC $95 \%$ : 0,75 a 1,28) que la eliminación por separado. Cabe aclarar que el término contaminación fluorescente hace referencia al uso de agentes fluorescentes en los estudios que simularon la contaminación por gérmenes por medio de estas sustancias. El uso de doble guante podría conducir a una menor contaminación viral o bacteriana en comparación con un solo guante (RR 0,34; IC 95\%: 0,17 a 0,66), pero no a menor contaminación fluorescente (RR 0,98; IC $95 \%$ : 0,75 a 1,28).

La instrucción oral adicional podría conducir a menos errores en el quitado del EPP (DM - 0,9; IC $95 \%-1,4 \mathrm{a}-0,4)$ y a menos puntos de contaminación (DM -5; IC 95\%-8,08 a -1,92).

La higiene adicional de los guantes con amonio cuaternario o blanqueador antes de su retiro podría disminuir la contaminación, pero no el desinfectante para manos a base de alcohol.

\section{Entrenamiento en el uso del equipo de protección}

El uso de simulación adicional por computadora podría generar menos errores en el retiro del equipo (MD -1,2; IC 95\%:-1,6 a $-0,7)$. Una videoconferencia sobre cómo ponerse el EPP podría conducir a mejores puntajes en las habilidades (DM 30,70; IC $95 \% 20,14$ a 41,26 ) que una conferencia tradicional. La instrucción cara a cara podría reducir más el incumplimiento de la guía de retiro del EPP (Odds Ratio [OR] 0,45; IC del $95 \%$ : 0,21 a 0,98) que proporcionar carpetas o videos solamente.

\section{Conclusiones}

Los autores de la revisión encontraron evidencia de baja a muy baja certeza de que cubrir más partes del cuerpo conduce a una 
mejor protección, aunque generalmente es más díficil de ponerse o quitarse, con menos comodidad para el usuario y, por lo tanto, incluso podría conducir a una mayor contaminación. Los tipos de EPP más transpirables puede conducir a una contaminación similar, pero pueden tener una mayor satisfacción del usuario.

Las modificaciones al diseño de EPP, como las pestañas para agarrar pueden disminuir el riesgo de contaminación. Para los procedimientos de colocación y retirada siguiendo las instrucciones del CDC, quitarse el guante y la bata en un paso, el uso de guantes dobles, las instrucciones habladas durante el procedimiento y la desinfección con guantes, podrían reducir la contaminación y aumentar el cumplimiento de estas recomendaciones.

La capacitación presencial en el uso de EPP podría reducir los errores más que aquella basada en carpetas o videos. Todavía necesitamos ECA de entrenamiento con seguimiento a largo plazo y estudios de simulación con más participantes.

Fuentes de financiamiento/conflicto de interés de los autores: Esta revisión recibió financiamiento por parte de organizaciones sin fines de lucro y gubernamentales: Cochrane UK (Reino Unido), Finnish Institute of Occupational Health (Finlandia) y National Institute for Occupational Safety and Health (EE.UU). Los autores negaron tener conflictos de interés.

\section{Comentario}

Las epidemias virales o las pandemias de infecciones respiratorias agudas, como la gripe o el síndrome respiratorio agudo severo, representan una amenaza mundial.

Una revisión sistemática Cochrane sobre intervenciones físicas para interrumpir o reducir la propagación de virus respiratorios $^{2}$, concluyó que las intervenciones simples y de bajo costo serían útiles para reducir la transmisión de virus respiratorios epidémicos. La evidencia proveniente de ECA grupales de alta calidad sugiere que la propagación de los virus respiratorios se puede prevenir mediante medidas higiénicas, como el lavado de manos, especialmente alrededor de niños más pequeños. Por otro lado, estudios de casos y controles aportaron evidencia que sugiere que la implementación de barreras de transmisión, aislamiento y medidas higiénicas son efectivas para contener las epidemias de virus respiratorios. Las máscaras quirúrgicas o los respiradores N95 fueron las medidas de apoyo más consistentes y completas, no inferiores a las máscaras quirúrgicas simples, pero si más caras, incómodas e irritantes para la piel. El efecto de agregar virucidas o antisépticos al lavado de manos habitual para disminuir la transmisión de enfermedades respiratorias sigue siendo incierto. Las medidas globales, como la detección de casos en los puertos de entrada, condujeron a un retraso marginal no significativo en la propagación y hubo pruebas limitadas de que el distanciamiento social era efectivo, especialmente si estaba relacionado con el riesgo de exposición.

Sin embargo, los trabajadores de la salud requieren precauciones adicionales para protegerse y prevenir la transmisión de estas enfermedades en la asistencia sanitaria. El cuidado de pacientes con COVID-19 incluye el uso apropiado de EPP; esto implica no sólo la selección del EPP adecuado, sino además el entrenamiento en cómo ponerlo, quitarlo y desecharlo.

El aumento de la demanda global, dará lugar a una mayor escasez a nivel mundial de EPP, siendo necesario asegurar que su uso EPP sea racionalizado y apropiado. En la selección del EPP a utilizar deberá tenerse en cuenta el riesgo de exposición (por ejemplo, el tipo de actividad) y la dinámica de transmisión del patógeno (por ejemplo, de contacto, gota o aerosol), es decir, deberá variar según el entorno y el tipo de personal y actividad ${ }^{3}$.

\section{Conclusiones de la comentadora}

La calidad de la evidencia es muy baja para todas las comparaciones. Esto significa que no podemos estar seguros acerca de las estimaciones de los efectos y, por lo tanto, es probable que los efectos reales puedan ser sustancialmente diferentes de los informados en esta revisión.

Los estudios de simulación impresionan ser una forma factible y relativamente simple de comparar diferentes tipos de EPP y descubrir cuál protege mejor contra la contaminación, siempre y cuando estén estandarizados en términos de exposición, medición de resultados y cuenten con un mayor número de participantes.

Por último, para descubrir cómo se comporta el EPP bajo exposición real, sería necesario un seguimiento prospectivo, a largo plazo, del PS involucrado en el tratamiento de pacientes con enfermedades altamente infecciosas, con un registro cuidadoso de EPP y riesgo de infección.

Yanina Avendaño [ Servicio de Medicina Familiar y Comunitaria, Hospital Italiano de Buenos Aires. yanina.avendano@hospitalitaliano.org.ar ]

Avendaño, Y Equipos de protección personal y métodos de capacitación con menor riesgo de autocontaminación o infección en el personal sanitario Evid Actual Pract Ambul. 2020;23(2):e002059. Comentado de: Verbeek JH et al. Personal protective equipment for preventing highly infectious diseases due to exposure to contaminated body fluids in healthcare staff. Cochrane Systematic Reviews 2020. Issue 4. Art. No.: CD011621. PMID: 32293717

\section{Referencias}

1. JH V, B R, S I, et al. Personal protective equipment for preventing highly infectious diseases due to exposure to contaminated body fluids in healthcare staff. Cochrane Database of Systematic Reviews. 2020;(4):CD011621. Available from: 10.1002/14651858.CD011621.pub4.

2. Jefferson T, Del-Mar CB, Dooley L, et al. Physical interventions to interrupt or reduce the spread of respiratory viruses. Cochrane Systematic Review Database. 2011;Available from: 10.1002/14651858.CD006207.pub4;https://doi.org/10.1002/14651858.CD006207.pub4.

3. World Health Organization. Rational use of personal protective equipment for coronavirus disease 2019 (COVID-19) ; 2020. Available from: https: //apps.who.int/iris/bitstream/handle/10665/331215/WHO-2019-nCov-IPCPPE_use-2020.1-eng.pdf?sequence=1\&isAllowed=y [Last access: 202004-29]. 